\title{
The Indices of Statokinetic Steadiness Among Disabled Children During Vertical Position Taking
}

\author{
Gross N.A. \\ Federal Scientific Center All-Russian Scientific Research \\ Institute of Physical Culture \\ Moscow, Russia \\ niinagross@yandex.ru
}

\author{
Sharova T.L. \\ Federal Scientific Center All-Russian Scientific Research \\ Institute of Physical Culture \\ Moscow, Russia \\ niinagross@yandex.ru
}

\begin{abstract}
The article defined the values of statokinetic steadiness indices among disabled children from 5 to 14 years old with motor disorders (ICP (infantile cerebral paralysis)) during vertical position taking. With the help of computer posturography at "Stabilan-1" apparatus the following tests were held: Romberg's test with one's eyes open and closed (83 observations among girls and 57 among boys) and test with head turn on the right and on the left (62 observations among girls and 40 among boys). We revealed great values variability in stabilometrics. The average values in "Frontal shift" and "Sagittal shift" indices among the children of both genders were close to the level of healthy children. The differences in the groups of boys and girls were in directions of coordinate deviations of pressure center (PC) on the right and on the left according to frontal or forward-back according to sagittal. We defined three times values increase of "The average speed of PC movement" index, 10 times "Ellipse area" index increase in comparison with the indices of healthy children.
\end{abstract}

Keywords-disabled children; statokinetic steadiness; stabilometrics indices; vertical position; rehabilitation.

\section{INTRODUCTION}

Disabled children have great individual differences in the initial motor skills, which they possess since childhood. Very often they have difficulties during vertical position holding. The ability of children to hold a vertical pose during the process of growing is the condition for correct musculoskeletal system development and body balance holding during external and internal conditions of environment change [1]. The absence of the ability to hold a vertical pose limits natural statokinetic reflexes and a child's movements formation at the very early stages of his development. Taking into account the peculiarities of vertical position holding by disabled children helps to form the programs of rehabilitation lessons by means of physical culture, taking into consideration individual characteristics of organism adaptation [2].
The aim of the research is to define the generalized statokinetic steadiness indices among disabled children with ICP diagnosis in order to create the concept of motor skills development by means of physical culture.

\section{RESEARCH METHODOLOGY}

We used stabiloanalyzer "Stabilan-1" [3]. The research was held at the beginning of rehabilitation lesson in the groups of girls and boys at the age of 5-14 with ICP, with different degree of motor disorders, who can stand still. We analyzed the following indices: "Frontal shift", "Sagittal shift", "The speed of PC movement”, "Ellipse area". Testing was held with eyes open and closed and with head turns on the right and on the left. In the test with the eyes open and closed 83 observations were held among girls and 57 observations among boys. With head turn on the right and on the left - 62 observations among girls and 40 among boys.

\section{RESULTS}

The research results helped to define quantitative values in "Frontal shift, mm", "Sagittal shift, mm", "The speed of PC movement $\mathrm{mm} / \mathrm{s}$ ", "Ellipse area, $\mathrm{mm}^{2}$ ", indices and also to reveal the peculiarities of vertical pose holding in the groups of girls and boys and their differences from healthy children.

In both groups we revealed great individual variation. It is proved by the increased values of the average quadratic deviation $( \pm \sigma)$. It is connected with different motor development characteristics of children, who have mid and severe forms of ICP.

Table 1 presents the average results of values according to "Frontal shift" and "Sagittal shift" indices and primary direction of PC shifts in these plane in tests with eyes open and closed and with head turn on the right and on the left. 
TABLE II. THE AVERAGE VALUES OF "THE AVERAGE SPEED OF PC MOVEMENT, MM/S” AND “ELLIPSE AREA, MM ${ }^{2 »}$ INDICES AMONG

TABLE I. THE AVERAGE VALUES OF "FRONTAL SHIFT, MM" AND "SAGITTAL SHIFT, MM" INDICES AMONG DISABLED CHILDREN DURING VERTICAL POSITION TAKING

\begin{tabular}{|c|c|c|c|c|}
\hline Indices & $\begin{array}{l}\begin{array}{l}\text { Open } \\
\text { eyes }\end{array} \\
\end{array}$ & $\begin{array}{c}\text { Closed } \\
\text { eyes }\end{array}$ & $\begin{array}{l}\text { Head on } \\
\text { the right }\end{array}$ & $\begin{array}{c}\begin{array}{c}\text { Head on } \\
\text { the left }\end{array} \\
\end{array}$ \\
\hline \multicolumn{5}{|c|}{ Frontal shift, mm } \\
\hline Girls under 14 & \multicolumn{2}{|c|}{$\mathrm{n}=83$} & \multicolumn{2}{|c|}{$\mathrm{n}=62$} \\
\hline $\mathrm{X} \pm \sigma$, shift on the right & $\begin{array}{l}3,7 \pm \\
16,9 \\
\end{array}$ & $\begin{array}{l}2,6 \pm \\
15,8 \\
\end{array}$ & $\begin{array}{l}4,4 \pm \\
14,8\end{array}$ & - \\
\hline $\mathrm{X} \pm \sigma$, shift on the left & - & - & - & $\begin{array}{l}-3,4 \pm \\
19,2 \\
\end{array}$ \\
\hline Boys under 14 & \multicolumn{2}{|c|}{$\mathrm{n}=57$} & \multicolumn{2}{|c|}{$\mathrm{n}=40$} \\
\hline $\mathrm{X} \pm \sigma$, shift on the right & - & $\begin{array}{c}2,9 \pm \\
16,9\end{array}$ & $\begin{array}{l}2,6 \pm \\
24,7\end{array}$ & $\begin{array}{l}0,1 \pm \\
27,6\end{array}$ \\
\hline $\mathrm{X} \pm \sigma$, shift on the left & $\begin{array}{c}-2,1 \pm \\
18,7 \\
\end{array}$ & - & - & - \\
\hline Healthy teen-agers [4] & 1,64 & 2,44 & - & - \\
\hline \multicolumn{5}{|c|}{ Sagittal shift, mm } \\
\hline Girls under 14 & \multicolumn{2}{|c|}{$\mathrm{n}=83$} & \multicolumn{2}{|c|}{$\mathrm{n}=62$} \\
\hline $\mathrm{X} \pm \sigma$ shift forward & $\begin{array}{l}3,1 \pm \\
14,7\end{array}$ & $1,3 \pm 10,2$ & - & - \\
\hline$X \pm \sigma$ shift back & - & - & $\begin{array}{c}-0,3 \pm \\
14,7 \\
\end{array}$ & $\begin{array}{c}-3,2 \\
\pm 16,7 \\
\end{array}$ \\
\hline Boys under 14 & \multicolumn{2}{|c|}{$\mathrm{n}=57$} & \multicolumn{2}{|c|}{$\mathrm{n}=40$} \\
\hline $\mathrm{X} \pm \sigma$ shift forward & $\begin{array}{l}5,1 \pm \\
18,4 \\
\end{array}$ & $\begin{array}{c}2,2 \pm \\
15,7 \\
\end{array}$ & & $\begin{array}{l}3,7 \pm \\
14,7 \\
\end{array}$ \\
\hline $\mathrm{X} \pm \sigma$ shift back & - & - & $\begin{array}{c}-2,1 \pm \\
17,6 \\
\end{array}$ & - \\
\hline Healthy teen-agers [4] & 2,18 & 3,12 & - & - \\
\hline
\end{tabular}

The results showed that the average values in "Frontal and sagittal shifts" indices among girls and boys were not too big and were close to the level of healthy children. In some cases during vertical position with children's eyes closed they had better steadiness, than with their eyes open. It is considered that this fact shows the possibility to compensate deviations owing to primary use proprioceptive abilities of analyzer system $[3,5]$.

During head turns on the right and on the left girls and boys had lower indices, than with their eyes closed and open. It can prove the fact that vertical position holding with the head turn is easier for them, than vertical position holding during eyes closed and open.

The characteristic of balance keeping among girls and boys depended on different orientation of deviations. In the groups of girls with their eyes open there was PC shift on the right -forward, among boys on the left-forward. With their eyes closed girls and boys had one direction shift- on the rightforward. During head turn on the right among girls and boys PC shift was on the right-backwards. During the head turn on the left PC shift among girls was on the left-backwards, among boys on the right-forward.

Table II shows the average values in "The average speed of PC movement, $\mathrm{mm} / \mathrm{s}$ " and "Ellipse area, $\mathrm{mm}^{2}$ " indices, received in tests with children's eyes open and closed and during head turn on the right and on the left.
DISABLED CHILDREN DURING VERTICAL POSITION TAKING

\begin{tabular}{|c|c|c|c|c|}
\hline Index & Open eyes & $\begin{array}{c}\text { Closed } \\
\text { eyes }\end{array}$ & $\begin{array}{l}\text { Head on } \\
\text { the right }\end{array}$ & $\begin{array}{c}\text { Head on } \\
\text { the left }\end{array}$ \\
\hline \multicolumn{5}{|c|}{ The average speed of PC movement, $\mathrm{mm} / \mathrm{s}$} \\
\hline - & \multicolumn{2}{|c|}{$\mathrm{n}=83$} & \multicolumn{2}{|c|}{$\mathrm{n}=62$} \\
\hline $\begin{array}{l}\text { Girls under } 14 \\
\mathrm{X} \pm \sigma\end{array}$ & $36,6 \pm 31,2$ & $36,8 \pm 28,8$ & $29,8 \pm 17,3$ & $32,0 \pm 18,4$ \\
\hline $\begin{array}{l}\text { Healthy girls at the } \\
\text { age of } 9(\mathrm{n}=20)) \\
{[5]}\end{array}$ & 10,7 & $14,8-$ & - & - \\
\hline $\begin{array}{l}\text { Boys under } 14 \\
X \pm \sigma\end{array}$ & $35,0 \pm 17,4$ & $38,1 \pm 20,1$ & $39,5 \pm 24,2$ & $36,8 \pm 20,6$ \\
\hline $\begin{array}{l}\text { Healthy boys at the } \\
\text { age of } 9(\mathrm{n}=12) \\
{[5]}\end{array}$ & 10,8 & 13,1 & - & - \\
\hline \multicolumn{5}{|c|}{ Ellipse area, $\mathrm{mm}^{2}$} \\
\hline- & \multicolumn{2}{|c|}{$\mathrm{n}=83$} & \multicolumn{2}{|c|}{$\mathrm{n}=62$} \\
\hline $\begin{array}{l}\text { Girls under } 14 \\
\mathrm{X} \pm \sigma\end{array}$ & $\begin{array}{c}1314 \pm \\
1074\end{array}$ & $\begin{array}{c}1420 \\
\pm 1300\end{array}$ & $884 \pm 842$ & $\begin{array}{c}1158 \pm \\
1584\end{array}$ \\
\hline $\begin{array}{l}\text { Healthy girls at the } \\
\text { age of } 9(\mathrm{n}=20) \\
{[5]}\end{array}$ & 134,7 & 160,6 & - & - \\
\hline $\begin{array}{l}\text { Boys under } 14 \\
X \pm \sigma\end{array}$ & $\begin{array}{c}2172 \pm \\
1993 \\
\end{array}$ & $\begin{array}{r}2129 \\
\pm 1822 \\
\end{array}$ & $\begin{array}{c}1869 \pm \\
1902 \\
\end{array}$ & $\begin{array}{c}1690 \pm \\
2166 \\
\end{array}$ \\
\hline $\begin{array}{l}\text { Healthy boys at the } \\
\text { age of } 9[5]\end{array}$ & 147,6 & 126,4 & - & - \\
\hline
\end{tabular}

In "The average speed of PC movement" index girls had no values decrease during their eyes closed (better balance), as it was in "Frontal and sagittal shifts" indices. During head turns on the right and on the left the differences were not significant. Among boys higher values (worse balance) of this index are in case of their eyes closed, during head turns there were no significant changes.

The values in "The average speed of PC movement" index in the groups of girls and boys with their eyes open and closed had three times increase relative to healthy children's values. It is possible that in case of such state organism experiences great functional tension. It is almost critical, and can be characterized as unstable.

The values of "Ellipse area" index among girls during their eyes closed were higher, than during their eyes open. With the head turn on the right less, than on the left. Among boys this index values in terms of their eyes open and closed didn't differ much. During the head turn on the right they were higher, which proved steadiness worsening.

Both groups of children had "Ellipse area" index values excess in comparison with healthy children (almost 10 times excess), which shows distinct state of tension during standing position holding. It is considered that the amplitude of movements increase during vertical position is characterized by effectiveness decrease of pose regulating processes, deficiency of muscle and joint afference of distal and proximal parts of legs and feet joints, decreased tone of antigravity muscularity $[6,7,8]$. 


\section{CONCLUSION}

1. We received quantitative values of steadiness indices among boys and girls at the age of 5 till 14, for whom great individual scatter in values is typical.

2. The average values of "Frontal and sagittal shifts" indices among girls and boys were close to the level of healthy children. The differences were in different orientation of PC coordinates deviations in frontal and sagittal planes.

3. The average values of "The average speed of PC movement" index in terms of children's eyes open and closed had three times excess relating to values of healthy people, which can characterize such balance as unsteady.

4. The average values in "Ellipse area, $\mathrm{mm}^{2}$ " indices in both groups of children were 10 times higher than the values of healthy children, which shows distinct state of unsteadiness.

5. It is reasonable to use research results in individual dynamic observations, where positive changes prove the effectiveness of rehabilitation lessons.

\section{References}

[1] Semenova K.A. Rehabilitation treatment of children with perinatal damage of nervous system and with infantile cerebral paralysis. Moscow: Law and order, "Great Russia, Heritage" series. 2007, 616.

[2] Gross N.A., Sharova T.L., Berkutova I.Yu., Zelenova N.I., Bukanova G.V. The influence of exercises, with the training simulators use, on disabled children's vertical steadiness formation. Sports science bulletin. Moscow. 2016, 4, pp. $44-50$.

[3] Skvortsov D.V. Stabilimetric research. - Moscow: Mera TSP. 2010, 192.

[4] Danilova R.I., Sobolev S.V. Vertical steadiness of 7-9 year-old children with hearing disorder in terms of visual analyzer deprivation. North (Arctic) Federal University bulletin. 2014, 2, pp. 45 - 51.

[5] Kurbatov Yu.N., Nemkova S.A., Zavadenko N.N. Stabilographic effectiveness estimation a complex rehabilitation treatment among children with nervous system disorders. Modern problems of science and education. Moscow. 2011, 6.

[6] S.V. Titov, Z.M. Kuznetsova. Rise of physical fitness level in special student's medical groups by means of athleticgymnastics. Pedagogicopshychological and medico-biological problems of physical culture and sport. 2009, 4(4), pp. 120-125. URL: http://www.vak.webtm.ru/images/vipuski/4-1/4.pdf

[7] Alexsandr S. Kuznetsov. Russian Professor's meeting. Russian Journal of Physical Education and Sport. 2019, 14(1), pp. 17-22. DOI: 10.14526/2070-4798-2019-14-1-18-24

[8] Shestakov M.P. Stabilometrics study in sport. Moscow: TVT Divizion. 2007, 106. 